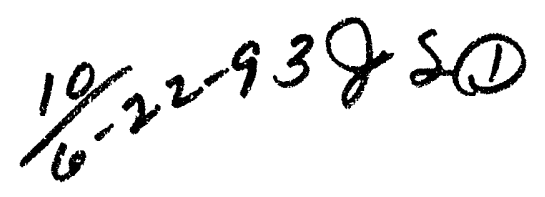

\title{
Pulse Modulator Developments in Support of Klystron Testing at SLAC
}

\author{
R. F. Koontz, R. Cassel, J. de Lamare, D. Ficklin, S. Gold, K. Harris \\ Stanfoŕd Linear Accelerator Center \\ Stanford, CA 94309 USA
}

\section{Abstract}

Several families of high power klystrons in S- and XBand are being developed in the Klystron Laboratory at SLAC. To support these developments, a number of new pulse modulators are being designed from scratch, or upgraded from existing laboratory test modulators. This paper outlines the modulator parameters available in the SLAC Klystron Laboracory, and discusses two new modulators that are under construction.

\section{BACKGROUND}

Thirty years ago, the first building constructed at the new site of the Stanford accelerator was the Klystron Test Lab. The sources of the microwave power needed to drive this massive accelerator were very much in doubt. The Test Lab was equipped with twelve line type modulators built by Ling for the purpose of testing new developmental klystrons and other components needing high power S-Band rf. Over the years, these test positions have been upgraded and radically changed to meet the needs of ongoing if development projects. Currently, the lab is supporting the continuing production of the $65 \mathrm{MW}$ pulsed klystrons that power the Stanford Linear Collider (SLC), and has developmental programs underway on both S- and X-band pulsed power sources. The Test Lab now has sixteen test positions of which five are dedicated to $R \& D$

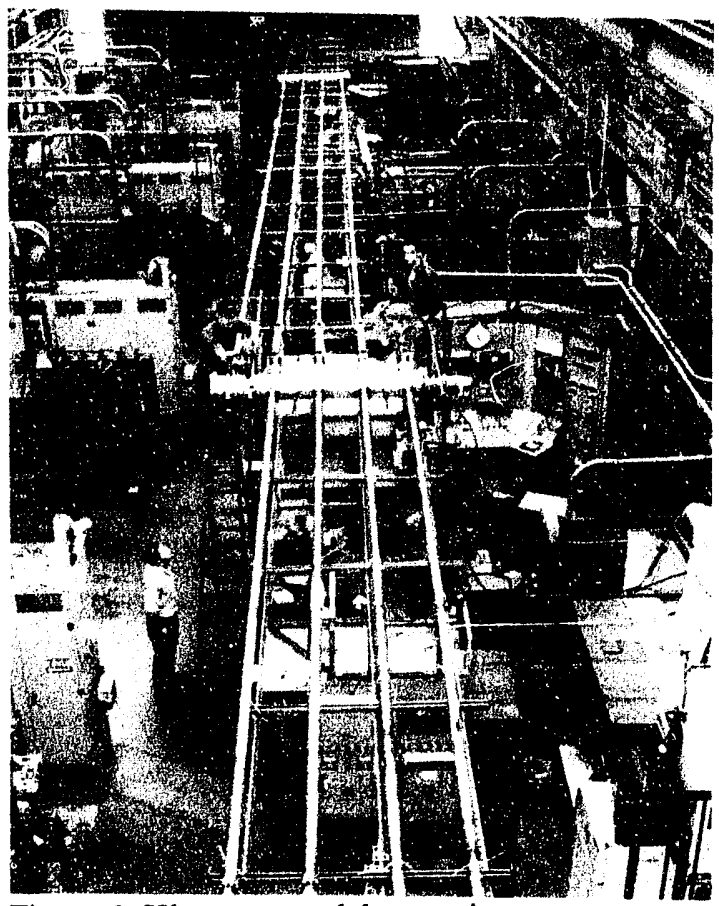

Figure 1. Klystron test lab overview.
* Supported by Department of Energy contract
DE-AC03-76SF00515. of new klystrons. The photograph in Fig. 1 shows the floor layout of the laboratory. Test Stand capabilities are listed below, and details of the new modulator developments are outlined in the paragraphs following.

\section{A. Production Test Stands}

Test Stands $1,5,7,9, \& 11$ are dedicated to $65 \mathrm{MW}$ production klystron testing. These test stands are conventional line type modulators with thyratron switching. Primary power supplies are variable transformer programmed $25 \mathrm{kV} \mathrm{DC}$ units that resonant charge two parallel section pulse lines. DeQing, cutting off the resonant charge when a reference voltage is reached, is used for regulation. When the thyratron fires, a $23 \mathrm{kV}$ pulse of $5 \mu \mathrm{s}$ ( $3 \mathrm{~dB}$ points) duration is supplied through a pulse cable to the klystron pulse transformer. The 15:1 transformer delivers a $350 \mathrm{kV}$ pulse to the cathode of the klystron. The klystron perveance is nominally 2 pperv, and this translates to a delivered pulse current of 414 amps. The primary current in the thyratron is in excess of 6,000 amps. An electrical layout of these modulators is shown in Fig. 2.

\section{$B$. Thyratron Test Stands}

In the last year there has been a major effort to secure multiple sources of reliable thyratrons for modulator service at SLAC. The SLC has 245 operating modulators that require thyratrons, and the failure rate of thyratrons in this service is about four per week. Currently, two manufacturers, ITT and EEV, are supplying thyratrons, and Litton is close to delivering a newly designed thyratron that should give long service. ITT and EEV are upgrading their thyratron designs as well. Three test stands in the Test Lab are dedicated to thyratron evaluation and qualification. Thyratron testing involves detailed monitoring of thyratron operating parameters. High Voltage Over Current faults are counted and automatically reset during processing and acceptance testing. Each test modulator oper-

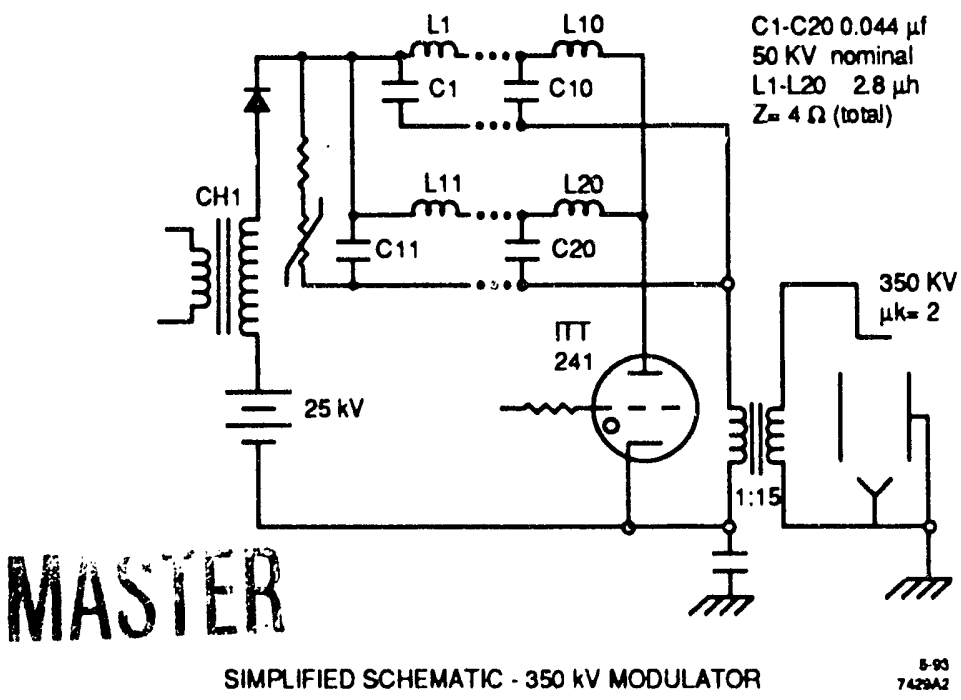

SIMPLIFIED SCHEMATIC - $350 \mathrm{kV}$ MODULATOR

$\sqrt{800}$

Figure 2. Standard pulse modulator schematic.

Presented at the Particle Accele: ator Conference (PAC 93), Washington, DC, May 17-20, 1993 


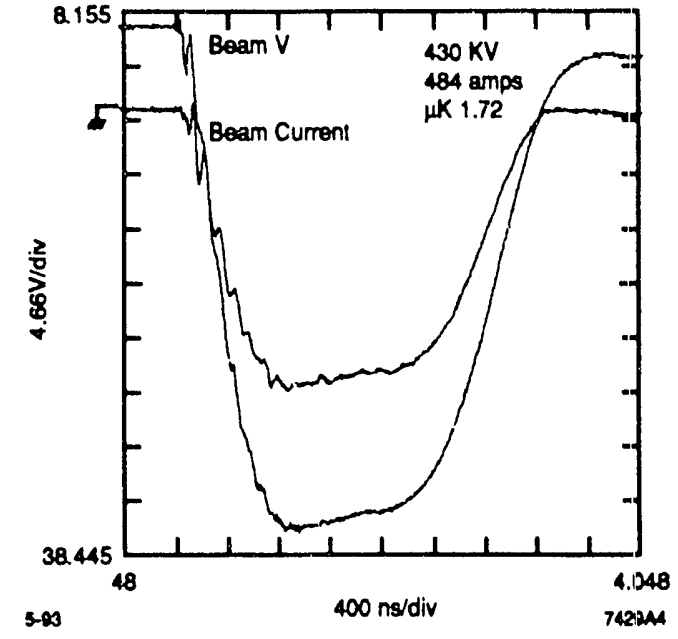

Figure 3. Test stand 8 beam pulse voltage.

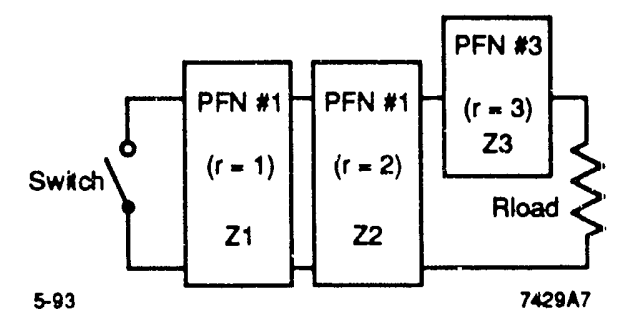

Figure 4. Test stand 3 Blumlein schematic

ates into a pulse transformer tank equipped with a glass-tubeenclosed liquid load, containing a detergent solution, in place of the actual klystron. These test stands are also used to dynamically test all pulse transformer-tank assemblies before klystrons are mated to the tanks.

\section{S-Band Resonant Ring - Window Test}

One test stand is dedicated to operation of an existing resonant ring which can circulate over $200 \mathrm{MW}$. The modulator in this test stand has an extended network that delivers a $6.5 \mu \mathrm{s}$ beam pulse. A 5045 klystron delivers up to $50 \mathrm{MW}$ of of $(5 \mu \mathrm{s})$ to the ring, or to a separate window test waveguide assembly. Windows were previously tested in the ring, but it has been found to be more effective to test windows with the full output of the klystron which acts as a lower impedance drive source than the high $\mathrm{Q}$ resonant ring. In the ring, fields collapse rapidly when a discharge occurs at a test window, and the window is not damaged. When driven directly from a klystron, the fields do not collapse, and the klystron drives energy into a window discharge, such that subsequent inspection shows it to be defective. Windows used on production klystrons go through this direct drive testing process.

\section{X-Band Resonant Ring Test Stand}

Two high voltage test stands have been dedicated to the development of high power X-Band klystrons. One of these test stands has been used intermittently to drive an X-Band resonant ring that can operate at over $300 \mathrm{MW}$ circulating power (Ref. 1). To allow this ring to be used regularly in component testing, a new, but completely conventional modulator and test position is under construction that will provide a $3 \mu$ seam pulse of up to $400 \mathrm{kV}$ to an experimental $\mathrm{X}$-Band klystron that will be dedicated to ring drive service. This test stand will be operational by August 1993.

\section{E. Medium Voliage $X-B$ and $R \& D$ Test Stands}

The two test stands mentioned above, 6 and 8 , have been upgraded with network modifications-ITT-303 12,000 amp thyratrons, and 20:1 ratio pulse transformer tanks close coupled to the modulators to produce $600 \mathrm{~ns}$ rise time beam voltage pulses up to $450 \mathrm{kV}$. The networks can be configured to produce pulses as short as $600 \mathrm{~ns}$, or as long as $1.7 \mu$ s. X-Band R\&D klystrons operate at a nominal perveance of $1.8 \mu$ perv. At full voltage, the thyratron must switch over $11,000 \mathrm{amps}$ from the network. The ITT-303 large cathode thyratron has this capability.

The electrical configuration of these two modulators is similar to that of the production modulators, but the layout is optimized to reduce stray inductance and capacitance. This permits the fast rise times obtained in the beam pulse image shown in Fig. 3

\section{F. $650 \mathrm{kV}, 1.2$ uperv Blumlein Test Stand for X-Band Klystron $R \& D$}

The parameters of this test modulator were presented (Ref. 2) by Cassel et al. This modulator design is under construction in the Klystron Test Lab in test stand position 3. The three section network in the Blumlein configuration is charged in the conventional resonant charging mode by a programmable $45 \mathrm{kV}$ DC power supply. The variable autotransformer of the original test stand is used for level control, and a new SCR switching bridge in the power supply primary is used to provide "soft start" capability. Later, this circuit will be used for direct voltage control. The three stage Darlington network that composes the pulse forming line delivers an output pulse of 1.5 times the peak charging voltage to the pulse transformer when the thyratron is fired. A block schematic of this network is shown in Fig.4. The use of this voltage multiplier network allows the thyratron to see only the PFN charging voltage of $85 \mathrm{kV}$ while delivering a network output voltage of $127 \mathrm{kV}$. With a conventional pulse line the output voltage would only have been $42 \mathrm{kV}$. A serious limitation to fast rise time is leakage inductance in high ratio pulse transformers. Using this Blumlein multiplier technique, a fast rise time pulse transformer of only 6:1 ratio can be employed in the system, and still produce klystron calhode beam pulses of over $650 \mathrm{kV}$. All components for this molulator are now in house including the pulse transformer, and low level network testing is underway. We expect this modulator to be assembled and ready for high power testing in the Fall of 1993.

\section{G. $550 \mathrm{kV}, 1.8$ uperv Test Stand for $150 \mathrm{MW}$ S-Band klystron Development}

Test Stand 13 is being modified to operate a $150 \mathrm{MW}$ SBand klystron, with microperveance 1.8 , at a beam voltage of $550 \mathrm{kV}$ maximum. The most expeditious and cost effective method of modification is to build a standard line-type modulator using as many of the existing modulator components as possible. The existing set up has a $25 \mathrm{kV}$ power supply and charging choke system, and $50 \mathrm{kV}$ thyratrons are available. A pulse transformer ratio of $1: 23$ and a Pulse Forming Network 


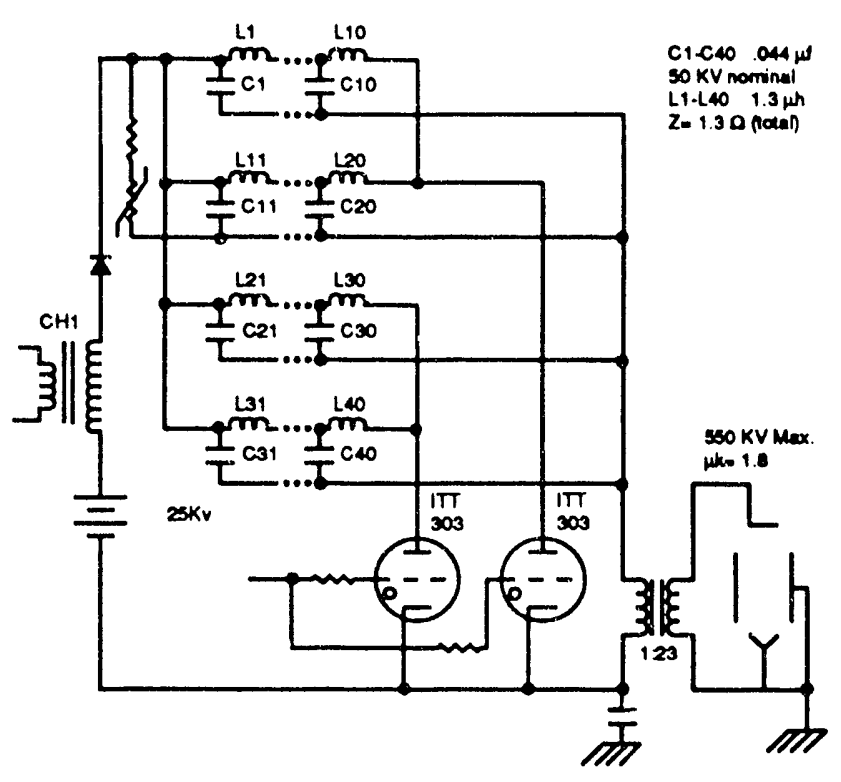

SIMPLIFIED SCHEMATIC-550 kV MODULATOR T4200

Figure 5. Test stand $3(550 \mathrm{kV})$ modulator schematic.

impedance of $1.3 \mathrm{ohms}$ was chosen to obtain the slight positive mismatch. Based on the PFN impedance, the reflected klystron impedance, and the required output voltage, the thyratron voltage (PFN voltage) will be $46 \mathrm{kV}$ which is a comfortable operating point for a $50 \mathrm{kV}$ thyratron. The total thyratron discharge current is 17,000 amperes. Two ITT Model 303 Thyratrons will be used to discharge the PFN.

Stangenes Industries of Palo Alto, Califormia is designing a pulse transformer with a 600 ns rise time $(10 \%$ to $90 \%)$ and $3.5 \mu$ s flat top for this application. The required PFN pulse width is $4.5 \mu \mathrm{s}$.

The rise time of the output pulse to the klystron is dominated by the rise time of the pulse transformer. However, a 10section PFN is needed so that the beam pulse width can be shortened, by removing sections, during initial turn on and processing of the klystron yet still maintain a usable pulse shape. The impedances are very low and the peak currents high in this type of conventional design. Wiring and component inductances can significantly effect the output pulse and system noise. These potential problems are addressed by:

a) using four parallel, ten-section PFNs and discharging each pair with a thyratron.

b) mechanically designing the PFNs, thyratrons, etc. in a symmetrical configuration with short leads to the pulse transformer that can be copper bus.

The four parallel PFN's, as shown in Fig. 6 enable each inductor to be four times larger than an equivalent single PFN structure. The calculated value for each inductor is $1.16 \mu \mathrm{Hen}$ rys. The inductors are designed for $1.3 \mu$ Henrys and can be tapped and fine tuned with a slug. Each of the inductors is in series with one of the forty capacitors. The capacitance of each section is nominally $0.045 \mu \mathrm{Farads}$, which is similar to the capacitors already in use. The plastic case capacitors manufactured today are significantly smaller than those in use at SLAC and can be made with much lower internal inductance $(35 \mathrm{nHy})$. Using $4 " \times 6$ " capacitors approximately 13 " long, the

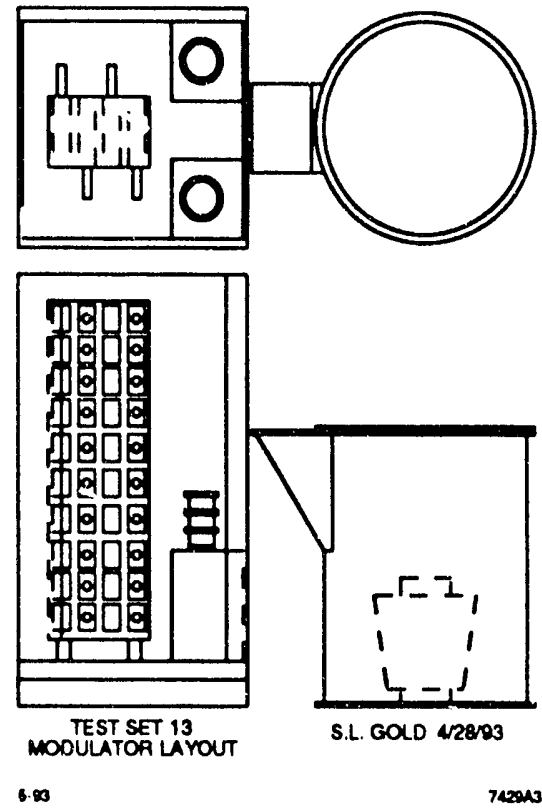

Figure 6. Test stand 13 modulator layout.

four Parallel PFN's can be packaged in the same space as the present systems.

To make room for all the inductors, the capacitors are alternated such that two PFN's face one direction and two face the opposite direction. This layout is shown in Fig. 7. Also shown is the placement of the thyratrons and the pulse transformer tank. Each thyratron discharges two PFN's. Because of the symmetry and close proximity of the components, the inductances can be minimized and somewhat equalized.

The pulse transformer and cathode end of the klystron are housed in a round tank. This tank will also be used on the 650 kV modulator.

\section{Other Test Lab Support Facilities}

The Test Lab is also home to two major testing facilities, the $70 \mathrm{kV}$, half-Megawatt CW rf test stand that is used for processing and qualifying PEP klystrons, and the X-Band accelerator Test Facility where X-Band power from experimental klystrons is used to power accelerator structures (Ref. 3). This facility is equipped with an electron gun and a spectrometer. A new 1.2 MW CW rf test stand is being planned for testing a B factory klystron.

\section{References}

[1] Component Development for X-Band Above $100 \mathrm{MW}$ W. R. Fowkes, et al 1991 IEEE Particle Accelerator Conf. SLAC-PUB-5544.

[2] $600 \mathrm{kV}$ Modulator Design for the SLAC Next Linear Collider Test Accelerator R. Cassel et al 20h Power Modulator Symposium, Myrule Beach, SC SLAC-PUB5851.

[3] Accelerator and RF System Developments for NLC A. E. Vlieks, et al This Conference SLAC-PUB-7415. 

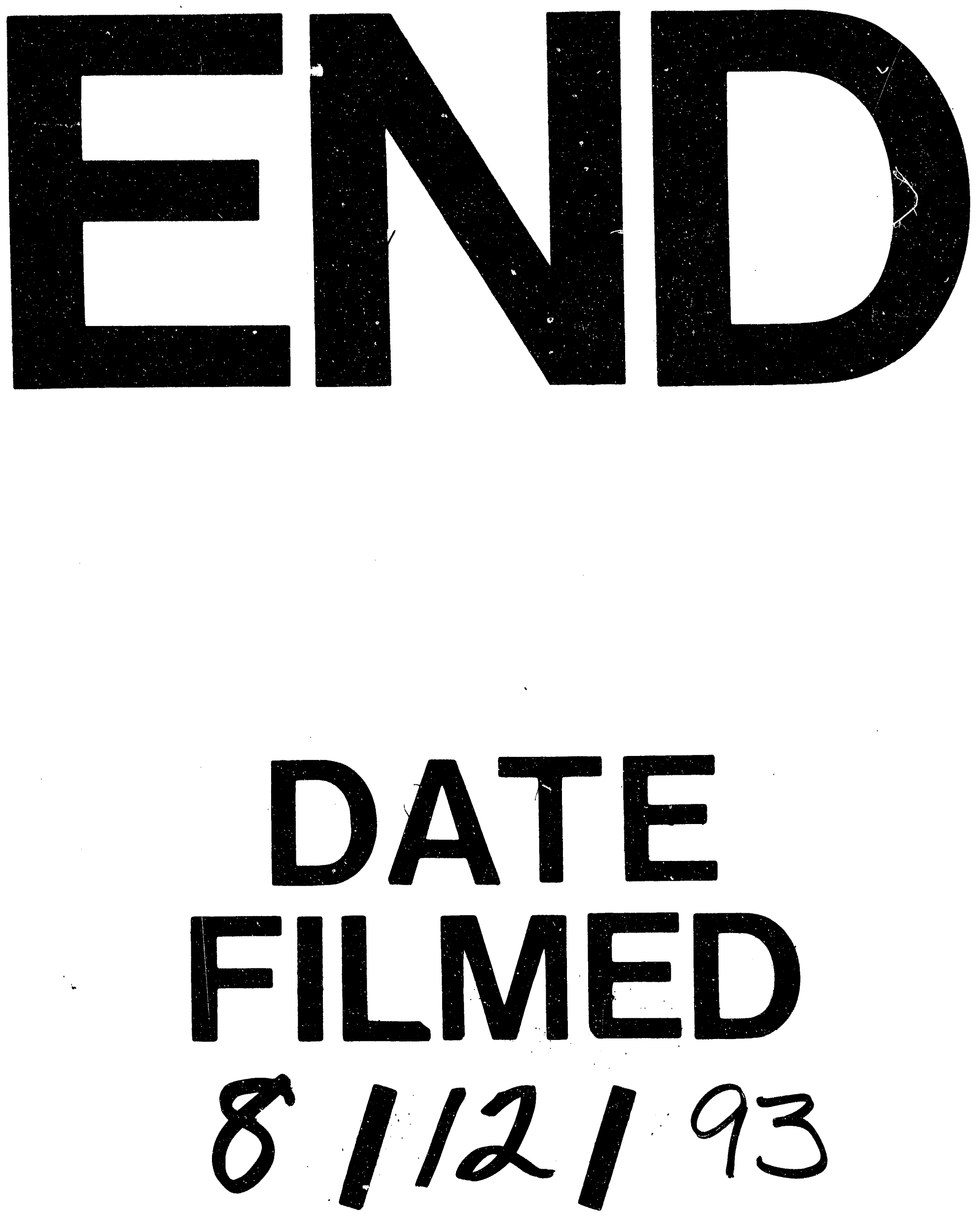
